\title{
ALFABETIZAÇÃO CIENTÍFICA NO CONTEXTO DAS SÉRIES INICIAIS
}

LEONIR LORENZETTI

Demétrio Delizoicov

\section{RESUMO}

A contribuição do ensino de Ciências Naturais nas Séries Iniciais do ensino fundamental para o processo de alfabetização dos alunos é analisada. Um resgate bibliográfico dos trabalhos desenvolvidos no Brasil, nas duas últimas décadas, sobre o assunto, bem como, daqueles produzidos em vários países e que giram em torno do tema alfabetização científica propiciaram o estabelecimento de uma compreensão para o processo de alfabetização científica a ser trabalhado nas Séries Iniciais. Enfatiza-se que a alfabetização científica é uma atividade vitalícia, sendo sistematizada no espaço escolar, mas transcendendo suas dimensões para os espaços educativos não formais, permeados pelas diferentes mídias e linguagens. É apresentada uma estrutura de programação na qual se destacam algumas iniciativas didáticometodológicas que, aliadas à apropriação do código escrito pelos alunos, podem contribuir ao processo de alfabetização científica que precisa ocorrer no âmbito da educação fundamental. Palavras-chaves: Alfabetização Científica; Ensino de Ciências Naturais; Educação em Ciências

\section{INTRODUÇÃO}

O tema ensino de ciências nas Séries Iniciais da educação fundamental, ainda que relativamente pouco explorado, está presente em trabalhos desenvolvidos no Brasil pela área de ensino e pesquisa em ensino de ciências. Um levantamento preliminar evidenciou uma produção acumulada desde o início da década de 80. Este levantamento que é representativo dos principais aspectos e questões investigadas aos quais os pesquisadores e grupos de ensino vêm se dedicando. Destacam-se trabalhos que podem ser classificados em dois grandes eixos, segundo os aspectos que privilegiam no seu enfoque do tema.

Um, cujo objeto é a "formação de professores" - inicial e continuada - tem uma trajetória percorrida ao longo das duas últimas décadas, tanto no que se refere à pesquisa como através de propostas de intervenção. Tais iniciativas são decorrentes do enfrentamento de problemas relativos às especificidades do ensino de ciências nas Séries Inicias por professores cujo perfil de formação e atuação é bem caracterizado e conhecido. Sem pretender esgotar as iniciativas localizadas neste eixo, constituem-se como referências as seguintes: Projeto Ensino de Ciências a Partir de Problemas da Comunidade (CAPES/UFRN, 1984; Pernambuco et alii, 1988); Projeto Física Para A Escola Normal (CAPES/UFRJ, 1986); Fracalanza et alii (1986); Angotti e Delizoicov (1990); Delizoicov (1993); Valle e Miranda (1993); Monteiro (1993); Vaz (1996); Mendes Sobrinho (1998); Ramos et alii (2000).

Um outro eixo tem como objeto o que poderíamos denominar de "materiais e métodos de ensino de ciências", destinados às Séries Iniciais. Em muitos casos os trabalhos localizados neste eixo se articulam com aqueles do eixo de formação de professores através de distintos níveis de aproximação. Tanto produzindo, testando e avaliando material instrucional destinado ao aluno e ao professor das Séries Iniciais, como relativos a processos de avaliação dos livros 
didáticos utilizados nas Séries Iniciais, estes trabalhos também têm uma trajetória, da qual se constituem exemplos: Pretto (1983); Dal Pian et alii (1985); Pernambuco et alii (1985); Frizzo e Marin (1989); Angotti e Delizoicov (1990); Lima (1992, 1992 a, 1993); Valle e Miranda (1993); Monteiro (1993); MEC (1994); Mohr (1994); Morais (1995); GEPECISC (1996); MEC (1996); Carvalho e Lima (2000).

Com a perspectiva de incrementar as discussões e ações no âmbito do ensino de ciências nas Séries Iniciais, neste artigo é apresentado um resgate do debate contemporâneo a respeito do papel da "alfabetização científica na constituição da cidadania", com a finalidade de obter parâmetros de referência que possam balizar as considerações sobre especificidades da alfabetização científica no início do Ensino Fundamental. Destacamos que a literatura relativa ao assunto "alfabetização científica" tem preocupações mais abrangentes do que a educação científica nas Séries Iniciais e, neste sentido, são praticamente ausentes referências explícitas que têm como foco o ensino nesta fase da formação dos alunos.

\section{ALFABETIZAÇÃO CIENTÍFICA E TÉCNICA}

Segundo Fourez (1994: 11) o tema alfabetização científica e técnica está em voga e vem sendo discutido em países Anglo-Saxões e em países do norte da Europa. O termo, de acordo com o autor, designa "um tipo de saber, de capacidade ou de conhecimento e de saber-ser que, em nosso mundo técnico-científico, seria uma contraparte ao que foi alfabetização no último século". Com respeito à educação escolar tem sido apontado que "a maioria dos educadores concorda que o propósito da ciência escolar é ajudar os estudantes a alcançar níveis mais altos de alfabetização científica" (Bybee, 1995: 28), existindo um acordo significativo da importância da alfabetização científica para a vida cotidiana de qualquer indivíduo.

No entanto, a alfabetização científica "tem muitas das características de um slogan educacional no qual o consenso é superficial, porque o termo significa coisas diferentes para pessoas diferentes" (Bingle \& Gaskell, 1994: 186). Desta forma são pertinentes algumas questões: qual o significado da alfabetização científica? Qual a sua importância para o currículo escolar? Como promovê-la?

Segundo Leal \& Souza (1997: 330), a alfabetização científica e tecnológica no Brasil é o reflexo do processo da globalização, "entendida como o que um público específico - o público escolar -- deve saber sobre ciência, tecnologia e sociedade (CTS) com base em conhecimentos adquiridos em contextos diversos (escola, museu, revista, etc.); atitudes pública sobre ciência e tecnologia e, informações obtidas em meios de divulgação científica e tecnológica”. Na Inglaterra, Estados Unidos e Portugal, este enfoque já vem sendo discutido há vários anos.

A alfabetização científica, segundo Krasilchik (1992: 06), constitui-se como uma das grandes linhas de investigação no ensino de ciências. Este movimento relaciona-se à mudança dos objetivos do ensino de ciências, em direção à formação geral da cidadania, tendo hoje papel importante no panorama internacional, estando "estreitamente relacionado à própria crise educacional e a incapacidade de a escola em dar aos alunos os elementares conhecimentos necessários a um indivíduo alfabetizado". 
Para Hurd (1998), a alfabetização científica envolve a produção e utilização da Ciência na vida do homem, provocando mudanças revolucionárias na Ciência com dimensões na democracia, no progresso social e nas necessidades de adaptação do ser humano. Hurd (1998) apresenta várias características que permitirão aos alunos adaptar-se ao mundo variável da Ciência e da Tecnologia e seu impacto no âmbito pessoal, social e econômico.

Segundo o mesmo autor, as características de uma pessoa cientificamente instruída não são ensinadas diretamente, mas estão embutidas no currículo escolar, em que os alunos são chamados a solucionar problemas, a realizar investigações, a desenvolver projetos em laboratório de apoio e experiências de campo. Estas atividades são compreendidas como preparação para o exercício da cidadania.

A alfabetização científica, segundo Shen (1975: 265), "pode abranger muitas coisas, desde saber como preparar uma refeição nutritiva, até saber apreciar as leis da física". São necessários especialistas para popularizar e desmitificar o conhecimento científico, para que o leigo possa utilizá-lo na sua vida cotidiana. Os meios de comunicação e, principalmente, as escolas podem contribuir consubstancialmente para que a população tenha um melhor entendimento público da Ciência.

Hazen \& Trefil (1995: 12) definem a alfabetização científica como 0 "conhecimento necessário para entender os debates públicos sobre as questões de ciência e tecnologia”. Este conceito envolve um conjunto de fatos, vocabulários, conceitos, história e filosofia do conhecimento científico.

A concepção de alfabetização científica que tem sido mais utilizada nos artigos consultados, foi definida por Miller (1983: 29), que analisou os conhecimentos dos indivíduos em relação a temas científicos, como radiação, aditivos químicos, astronomia:

“... quando se fala em alfabetização, normalmente não se percebe que a expressão ser alfabetizado apresenta dois significados diferentes: um, mais denso, estabelece uma relação com a cultura, a erudição. Por conseguinte, o indivíduo alfabetizado é aquele que é culto, erudito, ilustrado. $O$ outro fica reduzido à capacidade de ler e escrever".

No entanto, se o segundo significado da expressão ser alfabetizado - ser capaz de ler e escrever - for ampliado, a expressão alfabetização científica pode vir a ser entendida como a “capacidade de ler, compreender e expressar opinião sobre assuntos de caráter científico"(Miller, 1983: 30). Esse significado ampliado abre espaço para que se pergunte: O que vem a ser uma sociedade cientificamente alfabetizada? Cazelli (1992; 32), muito apropriadamente, questiona: "Uma sociedade habilitada para desempenhar funções nas áreas relacionadas à ciência ou uma sociedade preparada para adquirir visão geral e integrada do processo científico?”.

A definição de alfabetização científica como a capacidade do indivíduo ler, compreender e expressar opinião sobre assuntos que envolvam a Ciência, parte do pressuposto de que o indivíduo já tenha interagido com a educação formal, dominando, desta forma, o código escrito. Entretanto, complementarmente a esta definição, e num certo sentido a ela se contrapondo, partimos da premissa de que é possível desenvolver uma alfabetização científica nas Séries Iniciais do Ensino Fundamental, mesmo antes do aluno dominar o código escrito. Por outro lado, 
esta alfabetização científica poderá auxiliar significativamente o processo de aquisição do código escrito, propiciando condições para que os alunos possam ampliar a sua cultura.

Em todos os textos pesquisados e utilizados como referência, que são traduzidos do inglês para o português, o termo "literacy" é traduzido como "alfabetização", no Brasil e em Portugal. É importante destacar que a tradução correta do termo deveria ser "alfabetismo" e não alfabetização. Porém, optamos em manter a tradução do termo em inglês "cientific literacy" como "alfabetização científica" por julgarmos mais conveniente, uma vez que a alfabetização que defendemos não supõe um estágio término. Ela é uma atividade vitalícia. Outro aspecto que merece atenção é esclarecer que sempre que estivermos conceituando e definindo alfabetização científica nas Séries Iniciais, partimos do pressuposto que a alfabetização científica é um processo que tornará o indivíduo alfabetizado cientificamente nos assuntos que envolvem a Ciência e a Tecnologia, ultrapassando a mera reprodução de conceitos científicos, destituídos de significados, de sentidos e de aplicabilidade.

Shen (1975) distingue três noções de alfabetização científica. As diferenças entre elas referem-se não só aos seus objetivos, mas freqüentemente ao público considerado, ao seu formato e aos seus meios de disseminação. Estas três formas foram nomeadas de alfabetização científica "prática", "cívica" e "cultural".

Partindo do pressuposto de que grande parte da população vive em profunda pobreza, especificamente com pouco entendimento de Ciência, a "alfabetização científica prática" é aquela que contribuindo para a superação desta situação, tornaria o indivíduo apto a resolver, de forma imediata, problemas básicos que afetam a sua vida. Esta alfabetização deve proporcionar "um tipo de conhecimento científico e técnico que pode ser posto em uso imediatamente, para ajudar a melhorar os padrões de vida" (Shen, 1975: 265).

Assim, a "alfabetização científica prática" está relacionada com as necessidades humanas mais básicas como alimentação, saúde e habitação. Uma pessoa com conhecimentos mínimos sobre estes assuntos pode tomar suas decisões de forma consciente, mudando seus hábitos, preservando a sua saúde e exigindo condições dignas para a sua vida e a dos demais seres humanos. A alfabetização científica prática deveria estar disponível para todos os cidadãos, necessitando um esforço conjunto da sociedade para desenvolvê-la. Neste sentido, o ensino de ciências poderia ter seu papel que inicialmente independeria da criança saber ler e escrever. A alfabetização científica poderia apresentar um espectro muito amplo, incluindo abordagem de temas tais como agricultura, indústria, alimentação e, principalmente, sobre a melhoria das condições de vida do ser humano, ao mesmo tempo em que auxiliaria na apropriação do código escrito.

A "alfabetização científica cívica" seria a que torna o cidadão mais atento para a Ciência e seus problemas, de modo que ele e seus representantes possam tomar decisões mais bem informadas. Assim, o cidadão é capacitado a "tornar-se mais informado sobre a ciência e as questões relacionadas a ela, tanto que ele e seus representantes possam trazer seu senso comum para apreciá-lo e, desta forma, participar mais intensamente no processo democrático de uma sociedade crescentemente tecnológica” (Shen, 1975: 266). Destaca-se que a aquisição de um nível funcional de alfabetização científica cívica será um esforço mais demorado do que a alfabetização científica prática. 
Num outro nível de elaboração cognitiva e intelectual, estaria a "alfabetização científica cultural" procurada pela pequena fração da população que deseja saber sobre Ciência, como uma façanha da humanidade e de forma mais aprofundada. É o caso de profissionais não pertencentes à área científica, que passam a interessar-se por um dado assunto (engenharia genética, por exemplo) e, então, começam a ler, pensar e assinar revistas específicas para aprimorar seu conhecimento. "A alfabetização científica cultural é motivada por um desejo de saber algo sobre ciência, como uma realização humana fundamental; ela é para a ciência, o que a apreciação da música é para o músico. Ela não resolve nenhum problema prático diretamente, mas ajuda abrir caminhos para a ampliação entre as culturas científicas e humanísticas”(Shen, 1975: 267).

Um dos problemas da alfabetização científica cultural é que ela está disponível apenas para um número comparativamente pequeno de pessoas. Deveria haver um esforço muito grande para aumentar o acesso a este tipo de informação, para que a população possa desfrutar da Ciência em qualquer momento de sua vida. Existem hoje várias revistas que procuram divulgar a Ciência propiciando maior veiculação do conhecimento científico. Os jornais e revistas também informam constantemente a evolução da Ciência. Torna-se necessário, porém, que estes meios de comunicação possam circular livremente pelas escolas, colocando os alunos em contato com estas informações e, principalmente, utilizando-os como material pedagógico, constituindo-se também num desafio aos professores que precisam usá-lo adequada e criticamente.

A alfabetização científica cultural parece ser completamente destituída de objetivos utilitários. Ela pode exercer uma influência significativa sobre as opiniões atuais e futuras dos líderes comunitários que, por sua vez, poderão sistematizar estes conhecimentos com os demais membros da comunidade. Por outro lado, a alfabetização científica cívica poderá contribuir para minimizar a grande quantidade de superstições e crenças que permeiam a sociedade.

Depreende-se pois, que a alfabetização científica na perspectiva que está sendo apresentada não objetiva treinar futuros cientistas, ainda que para isso possa contribuir. Objetiva sim, que os assuntos científicos sejam cuidadosamente apresentados, discutidos, compreendendo seus significados e aplicados para o entendimento do mundo.

Aumentar o nível de entendimento público da Ciência é hoje uma necessidade, não só como um prazer intelectual, mas também como uma necessidade de sobrevivência do homem. É uma necessidade cultural ampliar o universo de conhecimentos científicos, tendo em vista que hoje se convive mais intensamente com a Ciência, a Tecnologia e seus artefatos.

Sob um outro prisma Bybee (1995) apresenta três dimensões da alfabetização científica que ocorreriam de acordo com uma evolução gradual. Denomina-as de alfabetização científica "funcional", "conceitual e processual" e "multidimensional".

A "alfabetização científica funcional" objetiva o desenvolvimento de conceitos, centrando-se na aquisição de um vocabulário, palavras técnicas, envolvendo a Ciência e a Tecnologia. Neste domínio da alfabetização científica, os alunos percebem que a Ciência utiliza palavras científicas apropriadas e adequadas. Assim, "de acordo com a idade dos educandos, fase de desenvolvimento, e o nível de educação, os estudantes deveriam estar aptos a ler e escrever passagens que incluem vocabulário científico e tecnológico” (Bybee, 1995: 29). 
Este autor argumenta que os professores têm dado na sua prática docente, e até reducionistamente, uma ênfase muito grande para esta dimensão da alfabetização científica, considerando que para desenvolver a alfabetização científica seja necessário atingir um grande número de conceitos, possuindo um amplo vocabulário científico. No entanto, destacamos que mesmo que o ensino de Ciências Naturais, em todos os níveis de educação, deva desenvolver o aprimoramento e ampliação do vocabulário científico dos estudantes, é necessário que este seja adquirido de forma contextualizada, na qual os alunos possam identificar os significados que os conceitos científicos apresentam.

$\mathrm{Na}$ "alfabetização científica conceitual e processual", os alunos já atribuem significados próprios aos conceitos científicos, relacionando informações e fatos sobre Ciência e Tecnologia. Destaca-se que o ensino não se resume a vocabulário, informações e fatos sobre Ciência e Tecnologia. Inclui habilidades e compreensões relativas aos procedimentos e processos que fazem da Ciência um dos caminhos para o conhecimento, ou seja, não se dicotomizam os processos e os produtos da Ciência.

A alfabetização científica, portanto, estendendo-se para além de vocabulário, preocupa-se com a apropriação de esquemas conceituais e métodos processuais, incluindo compreensões sobre Ciência. "Nós temos de ajudar os estudantes a desenvolver perspectivas de ciência e tecnologia que incluam a história das idéias científicas, a natureza da ciência e da tecnologia, e o papel da ciência e da tecnologia na vida pessoal e na sociedade" (Yager apud Bybee, 1995: 29). Este é o nível de "alfabetização científica multidimensional", quando os indivíduos são capazes de adquirir e explicar conhecimentos, além de aplicá-los na solução de problemas do dia-a-dia.

Sintetizando as posições de Shen e Bybee, podemos enfatizar que nas considerações de Shen (1975) estabelece-se o desenvolvimento de habilidades que serão utilizadas pelos indivíduos, de acordo com as necessidades e com o contexto. Elas não se resumem unicamente ao espaço escolar, sendo continuamente adquiridas e aprimoradas. Estas dimensões da alfabetização científica estão relacionadas aos objetivos, ao papel da alfabetização para a formação do cidadão. São atitudes e habilidades que serão incorporadas no dia-a-dia dos indivíduos, preocupando-se com a utilização dos conhecimentos científicos em contextos escolares ou não.

Por outro lado Bybee (1995) discute a alfabetização científica, estendendo seu conceito para um nível de compreensão dos significados que os conceitos científicos incorporam. A ênfase concentra-se nos processos de incorporação do conhecimento científico, centrando-se no processo ensino-aprendizagem, de como os alunos compreendem a Ciência. As categorias por ele estabelecidas estão relacionadas com o ambiente escolar.

\section{EDUCAÇÃO ESCOLAR E ALFABETIZAÇÃO CIENTÍFICA}

Parece claro que, apesar de ter um papel, a escola sozinha, isolada, não consegue alfabetizar cientificamente seus alunos. Lucas e Ucko (apud Cazelli (1992)) argumentam, com base nas propostas de Shen (1995), que as escolas não têm condições de proporcionar à sociedade todas as informações científicas que os alunos necessitam para compreender o seu mundo em mudança. "Os cursos escolares de ciência não podem proporcionar aos cidadãos todas as informações científicas que eles necessitarão ao longo de suas vidas, para compreender 
o seu mundo em mudanças, ou para participar das decisões sobre questões políticas influenciadas pela ciência e tecnologia" (Lucas apud Cazelli, 1992: 55).

Se a escola não pode proporcionar todas as informações científicas que os cidadãos necessitam, deverá, ao longo da escolarização, propiciar iniciativas para que os alunos saibam como e onde buscar os conhecimentos que necessitam para a sua vida diária. Os espaços não formais compreendidos como museu, zoológico, parques, fábricas, alguns programas de televisão, a Internet, entre outros, além daqueles formais, tais como bibliotecas escolares e públicas, constituem fontes que podem promover uma ampliação do conhecimento dos educandos. As atividades pedagógicas desenvolvidas que se apoiam nestes espaços, aulas práticas, saídas a campo, feiras de ciências, por exemplo, poderão propiciar uma aprendizagem significativa contribuindo para um ganho cognitivo.

Segundo Cobern (1995), a alfabetização científica não é uma característica que os estudantes adquirem automaticamente com êxito completo nas aulas de ciências. Os estudos desenvolvidos com alunos da nona-grade, nos Estados Unidos - o equivalente a $8^{a}$ série do Ensino Fundamental no Brasil -, demonstraram o pouco envolvimento do conhecimento da ciência escolar em discussões sobre o mundo natural. "Eles parecem separar o conhecimento e as habilidades adquiridas na escola do seu mundo fora da sala de aula" (Cobern, 1995: 28).

Os alunos não são ensinados como fazer conexões críticas entre os conhecimentos sistematizados pela escola com os assuntos de suas vidas. Os educadores deveriam propiciar aos alunos a visão de que a Ciência, como as outras áreas, é parte de seu mundo e não um conteúdo separado, dissociado da sua realidade.

As escolas, através de seu corpo docente, precisam elaborar estratégias para que os alunos possam entender e aplicar os conceitos científicos básicos nas situações diárias, desenvolvendo hábitos de uma pessoa cientificamente instruída.

\section{A ALFABETIZAÇÃo CIENTÍFICA NAS SÉRIES INICIAIS}

Ao considerar as especificidades da educação escolar, particularmente nas Séries Iniciais da educação fundamental, o papel da alfabetização ocupa lugar privilegiado, como não poderia deixar de ser. Soares (1998: 17), por exemplo, ao discorrer sobre o processo de alfabetização destaca que a leitura e a escrita "traz conseqüências sociais, culturais, econômicas, cognitivas, lingüísticas, quer para o grupo social em que seja introduzida, quer para o indivíduo que aprenda a usá-la”.

Neste sentido, "a alfabetização é uma ação de intervenção política e um processo de construção do entendimento sobre o assunto. Trata-se de um processo multidimensional que envolve questões cognitivas, lingüísticas, afetivas e sócio-culturais, com cujo desenvolvimento se pretende instrumentalizar o sujeito a fazer uma leitura mais objetiva do mundo, reescrevendo-o sob sua ótica e ampliando sua condição de agente transformador" (Grupo de Alfabetização, 1991: 06).

A alfabetização, para Soares (1985), é um processo permanente, que se estenderia por toda a vida, que não se esgotaria na aprendizagem da leitura e da escrita. Faz parte da natureza humana a busca incessante por novos conhecimentos, e esta busca permanente faz com que o homem produza novos conhecimentos constantemente, sempre mediados pela linguagem, oral ou 
escrita. É preciso diferenciar os processos de aquisição da língua (oral e escrita) e o desenvolvimento da língua (oral e escrita). O desenvolvimento da língua é um processo que não tem fim, e que dura a vida toda.

Etimologicamente, alfabetizar significa "levar à aquisição do alfabeto, ou seja, ensinar o código da língua escrita, ensinar as habilidades de ler e escrever" (Soares, 1985: 20). Ao se considerar esta dimensão a alfabetização se constituiria num processo de aquisição do código escrito, das habilidades de leitura e de escrita, levando o debate a se desenvolver em torno dos significados que os termos ler e escrever apresentam em nossa língua. Neste caso, a partir de argumentos apresentados por Soares (1985: 21) pode-se conceituar a alfabetização como um "processo de representação de fonemas em grafemas, e vice-versa, mas é também um processo de compreensão/expressão de significados através do código escrito". Este conceito de alfabetização que inclui também um processo de compreensão e expressão de significados será empregado para balizar as considerações a respeito do ensino de ciências nas Séries Iniciais, enquanto um processo que deve contribuir para alfabetizar cientificamente os alunos.

Por outro lado, considerando que o domínio do sistema de correspondência entre grafemas e fonemas é condição necessária, mas não suficiente para formar o alfabetizado e que "o processo de alfabetização deve, desde o início, possibilitar que o aluno desenvolva a compreensão do caráter simbólico da escrita (instrumento que serve para transmitir idéias, emoções, impressões etc.), além de identificar todas as possibilidades sociais de seu uso" (Leite \& Souza, 1995: 16), estamos aproximando o conceito de alfabetização científica ao que tem sido denominado de letramento. Este conceito, elaborado nos anos oitenta, é compreendido como " 0 resultado da ação de ensinar ou de aprender a ler e escrever: o estado ou a condição que adquire um grupo social ou um indivíduo como conseqüência de ter-se apropriado da escrita" (Soares, 1998: 18).

Pode-se dizer que o letramento é o uso que as pessoas fazem da leitura e da escrita em seu contexto social. Convivendo com uma variedade muito grande de informações, almeja-se que as pessoas saibam compreender os significados que os textos propiciam, incorporando-os na sua prática social. O indivíduo poderá fazer uso competente e freqüente da leitura e da escrita em seu trabalho, em casa, no seu lazer, etc.

É nossa compreensão que esta conceituação de letramento, transcendendo a de alfabetização, será de fundamental importância para o entendimento da alfabetização científica para as Séries Iniciais. A categoria letramento em Ciências refere-se à forma como as pessoas utilizarão os conhecimentos científicos, seja no seu trabalho ou na sua vida pessoal e social, melhorando a sua vida ou auxiliando na tomada de decisões frente a um mundo em constante mudança.

Assim sendo, a alfabetização científica que está sendo proposta preocupa-se com os conhecimentos científicos, e sua respectiva abordagem, que sendo veiculados nas primeiras séries do Ensino Fundamental, se constituam num aliado para que o aluno possa ler e compreender o seu universo. Pensar e transformar o mundo que nos rodeia tem como pressuposto conhecer os aportes científicos, tecnológicos, assim como a realidade social e política. Portanto, a alfabetização científica no ensino de Ciências Naturais nas Séries Iniciais é aqui compreendida como o processo pelo qual a linguagem das Ciências Naturais adquire 
significados, constituindo-se um meio para o indivíduo ampliar o seu universo de conhecimento, a sua cultura, como cidadão inserido na sociedade

A partir desta compreensão propomos a abordagem sistemática de um amplo leque de atividades, articulado com o planejamento escolar. O pressuposto é que a escola, dissociada do seu contexto, não dá conta de alfabetizar cientificamente. Permeando-a existe uma série de espaços e meios que podem auxiliar na complexa tarefa de possibilitar a compreensão do mundo. Garante-se, no entanto, a especificidade do trabalho educativo escolar na medida em que a atuação docente, mais que solicitada, é necessária para o planejamento e condução do que se propõe.

Dentre outras atividades possíveis de serem desenvolvidas destacamos as seguintes: o uso sistemático da literatura infantil, da música, do teatro e de vídeos educativos, reforçando a necessidade de que o professor pode, através de escolha apropriada, ir trabalhando os significados da conceituação científica veiculada pelos discursos contidos nestes meios de comunicação; explorar didaticamente artigos e demais seções da revista Ciência hoje das Crianças, articulando-os com aulas práticas; visitas a museus; zoológicos, industrias, estações de tratamento de águas e demais órgãos públicos; organização e participação em saídas a campo e feiras de Ciências; uso do computador da Internet no ambiente escolar.

A organicidade destas atividades pode ser garantida através de um planejamento que contemple a abordagem de conteúdos científicos estruturados a partir de "conceitos primitivos" e alguns "conceitos unificadores"(Pernambuco et alii, 1988; Delizoicov e Angotti, 1990; Angotti, 1991; São Paulo, 1992), os "conteúdos procedimentais"(Oró, 1999) e os conteúdos atitudinais.

Por sua vez, a sala-de-aula se constitui numa oportunidade privilegiada para a sistematização do conhecimento que está sendo veiculado através das várias ações promovidas. O uso adaptado de três "momentos pedagógicos", quais sejam, "problematização inicial, organização do conhecimento e aplicação do conhecimento" (Delizoicov e Angotti, 1990; Delizoicov, 1991; São Paulo, 1992) repercutem numa opção didático-metodológica com a qual o professor pode estruturar o seu trabalho docente, particularmente aquele promovido durante as suas aulas.

A especificidade da contribuição para o processo educativo escolar das atividades enunciadas tem sido considerada em alguns trabalhos.

A utilização de livros de literatura infantil, que tenham alguma relação com a Ciência, pode ser uma das formas de desenvolver a alfabetização e a alfabetização científica. "Incentivar a leitura de livros infanto-juvenis sobre assuntos relacionados às ciências naturais, mesmo que não sejam sobre os temas tratados diretamente em sala de aula, é uma prática que amplia os repertórios de conhecimentos da criança, tendo reflexos em sua aprendizagem"( Brasil, 1997a: 124).

Cagliari (1988), ao discutir a leitura nas Séries Iniciais, afirma que os professores deveriam ler algo diariamente para seus alunos. "Não ler só histórias, mas também coisas sérias, como uma notícia, um texto científico ou tecnológico, por exemplo, a história de quem inventou a lâmpada, a máquina de escrever, etc. Ler não apenas uma história onde os personagens são animais.... mas também texto de zoologia a respeito dos animais." (Cagliari, 1988: 09). Nestas ocasiões, mais próprias para a etapa onde o código escrito ainda não é completamente dominado pelos alunos, textos com estas qualidades poderiam auxiliar a 
explorar as características dos conceitos primitivos - espaço, tempo, matéria viva e não viva - e um dos conceitos unificadores, qual seja o de "processo de transformação". (Angotti, 1991; São Paulo, 1992).

Já para os alunos, que começam a dominar o código escrito, a leitura propicia o desenvolvimento cognitivo do educando, abrindo uma janela para conhecimentos que a conversação sobre outras atividades cotidianas não consegue comunicar. "Ela permite estabelecer associações esclarecedoras entre a experiência dos outros e a sua própria estrutura de história contada, pelas questões e comentários que ela sugere, pelos resumos que provoca, ela ensina a compreender melhor os fatos e atos, a melhor organizar e reter informações, a melhor elaborar os roteiros e esquemas mentais" (Morais, 1996: 171).

Relativamente à abordagem da conceituação científica e o seu significado, o professor poderá organizar a leitura, planejando-a de modo a identificar, explicitar e explorar os conceitos primitivos de espaço, tempo, matéria viva e não viva, e os conceitos de processo de transformação e escala que estejam compondo o discurso do texto.

A revista Ciência Hoje das Crianças, que compõem uma das referências do banco do GEPECISC (1996), é uma publicação da Sociedade Brasileira para o Progresso da Ciências (SBPC), editada desde a década de oitenta, objetivando a divulgação do conhecimento científico. "A revista tem caráter multidisciplinar e publica, sob as formas mais variadas, temas relativo às ciências humanas, exatas, biológicas e à cultura" (Souza et alii., s/d: 04). A revista apresenta uma linguagem capaz de propiciar conhecimentos àqueles que estão se iniciando na Ciência e na cultura. Segundo Souza (et alii. s/d), a revista se propõe a ser extracurricular e ter uma circulação ampla na sociedade. A Fundação de Assistência ao Estudante (FAE) incorporou a revista Ciência Hoje das Crianças no rol de publicações distribuído na rede pública de ensino do Brasil, adquirindo, a revista, um caráter paradidático que muito pode contribuir para a melhoria do ensino de Ciências Naturais.

A leitura das revistas e dos suplementos de jornais destinados ao público infantil deverá ser incentivado pelos professores para a busca de novas informações. Esta busca de novas informações é uma das características da alfabetização científica cultural proposta por Shen (1975). Assim, a revista Ciência Hoje das Crianças pode ser utilizada como "fonte de pesquisa para a produção de textos, leitura livre, fonte para experimentos e mesmo treinamento de leitura na sala de aula" ( Souza et alii., s/d: 05).

A produção crescente de vídeos educativos tem contribuído significativamente para um trabalho na perspectiva do desenvolvimento da alfabetização científica cultural (Shen, 1975) e multidimensional (Bybee, 1995). Através dos documentários os alunos têm a oportunidade de ampliar a sua cultura, o seu universo de conhecimentos. Há excelentes documentários, também veiculados pela TV sobre a Ciência, que apresentam os mais variados assuntos científicos com clareza e profundidade, aliados a uma fotografia que prende a atenção, principalmente das crianças. De modo semelhante aos textos, o uso planejado e estruturado destes vídeos pode ser efetivado pelo professor.

A utilização do teatro em sala de aula constitui-se em uma outra atividade que pode auxiliar a compreensão dos conteúdos das Ciências Naturais. Através da encenação de peças teatrais os alunos podem ser conscientizados da importância da preservação do meio ambiente, da preservação da flora e da fauna, dos cuidados com o corpo, entre outros. Esta atividade torna- 
se viável a partir das experiências que o aluno traz antes de chegar à escola. Nos jogos de fazde-conta a criança traz uma enorme capacidade de teatralidade como um potencial e como uma prática espontânea, que urge ser utilizada pelos professores. Assim, espera-se que, através do teatro, "o aluno se aproprie, crítica e construtivamente, dos conteúdos sociais e culturais de sua comunidade mediante as trocas com os seus grupos" (Brasil, 1997b: 84).

Através do teatro, a criança tem a possibilidade de se transformar no personagem, vivendo intensamente os fatos estudados, compreendo os significados que eles apresentam. Os alunos podem assumir a representação dos astros que compõem o sistema solar, 0 movimento das plantas e dos seres vivos, emitindo sons e movimentos característicos. Neste momento tem a possibilidade de desenvolver a oralidade, a memorização, contribuindo para a ampliação da cultura. Além dos procedimentos e atitudes envolvidos, os parâmetros para o desenvolvimento conceitual são fornecidos pelos conceitos de espaço, tempo, matéria viva e não viva e os processos de transformação e escala.

Os museus de Ciência e Tecnologia são apontados como "espaços dinâmicos e populares, com atributos particulares para a aprendizagem da ciência, difíceis de serem replicados nos espaços escolares tradicionais, e que não estão disponíveis em qualquer lugar" (Cazelli, 1992: 21). As atividades apresentadas nestes espaços aumentam a curiosidade, 0 senso de observação, a criatividade e o interesse pela Ciência. Cazelli (1992: 152) afirma que os museus interativos de Ciência e Tecnologia desenvolvem, principalmente, a alfabetização científica prática e cultural, "uma vez que funcionam tanto como meio para aquisição de novas informações sobre assuntos científicos, quanto como meio para aprimorar conhecimentos adquiridos".

Durante as visitas aos museus, e as outras formas de saídas a campo, atividades práticas, os alunos aprendem por meio da interação que se estabelece com os professores, com os adultos, contando com a disposição de objetos e com a relação entre experiência e o seu conhecimento. Desta forma, ao retornarem à escola, os professores ao sistematizarem este conhecimento possibilitam o seu aprofundamento e a construção de outros saberes. A sistematização dos conhecimentos é, portanto, uma das tarefas fundamentais da escola e da atuação docente para que este processo de alfabetização ocorra, de modo a propiciar significado e sentido ao conhecimento que está sendo apropriado pelo aluno.

As pequenas excursões, que podem ser realizadas desde as primeiras séries do Ensino Fundamental, constituem-se atividades que auxiliam a ampliação da cultura científica dos educandos. Esta atividade deve estar estritamente relacionada com os conteúdos que estão sendo desenvolvidos em sala de aula. Sugere-se que as saídas tenham um roteiro previamente elaborado juntamente com os alunos, enfatizando os objetivos da excursão, os aspectos que devem ser analisados e anotados. Estas informações serão fundamentais para a conclusão dos trabalhos. Também o professor deverá conhecer o local previamente, avaliando as condições de segurança e os locais para a realização dos trabalhos, selecionando os materiais e determinando o tempo necessário para a realização de cada atividade.

Através das saídas a campo, os alunos estarão realizando observações diretas, contribuindo para a alfabetização científica, na medida em que permitem, de modo sistemático, mediar o uso dos conhecimentos para melhor compreender as situações reais. Os alunos 
acabam utilizando todos os sentidos e não apenas a observação visual. "Além disso o contato com ambientes, seres vivos, áreas em construção, máquinas em funcionamento, possibilita observações de tamanho, formas, comportamentos e outros aspectos dinâmicos, dificilmente proporcionados pelas observações indiretas"(Brasil, 1997a: 122).

As aulas práticas, para além do que têm sido denominada de atividades experimentais, podem se constituir em atividades significativas, à medida que promovam a compreensão e ampliação do conhecimento em estudo. Muito se tem criticado a realização de experimentos como "receita", repetindo uma seqüência de passos determinada pelo professor, cabendo ao aluno a simples execução mecânica da experiência ou a simples observação e acompanhar os resultados da atividade realizada pelo professor. No entanto, ao se propor o uso didático de atividades que envolvam práticas experimentais:

"Não se trata de privilegiar o desenvolvimento de habilidades motoras genéricas e desprovidas de conteúdo, tampouco de outras habilidades específicas associadas a determinadas técnicas laboratoriais, mas de oportunizar ao aluno o acesso às práticas de laboratório inseridas num contexto claramente problematizado, decorrente de uma postura investigativa que se deflagra através de um projeto. Assim, trata-se de concebê-las como mais um meio para se alcançar a aprendizagem significativa" (Giordan, 1997: 323).

O desenvolvimento dos conteúdos procedimentais será de fundamental importância durante a realização das aulas práticas. Observar atentamente o fenômeno em estudo, estabelecer hipóteses, testá-las via experimento, registrar os resultados, permite que os alunos ajam de forma ativa sobre o objeto de estudo, possibilitando uma melhor compreensão do experimento

Os computadores têm sido apontados como ferramentas imprescindíveis na educação de nossos jovens. Observa-se diariamente que a informática penetrou grandemente em todos os setores da sociedade, e a escola não pode ficar alheia à importância do computador para a melhoria do ensino de modo geral. Muito se tem discutido sobre o papel do computador no processo ensino-aprendizagem. O computador por si só não constitui uma atividade significativa. Ele é um meio, um auxiliar, um facilitador do ato pedagógico. A forma, a ênfase, que o professor dispensará a estas informações será o diferencial para uma melhor compreensão dos conteúdos escolares. Silva Filho (1998: 116) afirma que o computador constitui-se "em um excelente instrumento para todas as pessoas que interagem com a criança desde que estejam convictas de que é a qualidade das interações que definirá as possibilidades e os limites deste instrumento no processo educativo".

A internet tem sido apontada como um meio de ampliação de conhecimentos. Caberá ao professor, juntamente com os alunos, localizar as fontes de informação, proporcionando situações nas quais possam interagir com outras fontes de informação. Neste sentido, a internet pode possibilitar a ampliação da cultura, em todas as dimensões da alfabetização científica, especialmente da dimensão da alfabetização cultural, proposta por Shen (1975).

O uso do computador na escola pode auxiliar no processo de desenvolvimento e aprendizagens das crianças. Estes procedimentos localizam-se na "ampliação das experiências de vida, na diversificação destas experiências e na tentativa de não tentar limitar 
tais experiências a um padrão, um tipo, um recorte da realidade" (Silva Filho, 1998: 115; grifos no original). Este autor argumenta, ainda, que a interação da criança com o computador e os seus recursos pode contribuir para o desenvolvimento das funções psicológicas superiores. Assim, os computadores, através de jogos, simulações, internet, entre outros, podem contribuir para a socialização, na ampliação das experiências e do conhecimento que as crianças constróem do mundo, contribuindo para a ampliação da cultura, "bem como de veículo de democratização da informação e das relações" (Silva Filho, 1998: 120), respeitando as condições e especificidades da Educação Infantil e das Séries Iniciais.

\section{CONSIDERAÇÕES FINAIS}

Defendemos a premissa de que a alfabetização científica pode e deve ser desenvolvida desde o início do processo de escolarização, mesmo antes que a criança saiba ler e escrever. Nesta perspectiva 0 ensino de ciências pode se constituir num potente aliado para 0 desenvolvimento da leitura e da escrita, uma vez que contribuí para atribuir sentidos e significados às palavras e aos discursos.

É necessário, contudo, que alguns desafios sejam enfrentados.

De imediato as formas de organização do cotidiano escolar precisam se adequar, particularmente o das escolas de ensino fundamental das redes públicas. As demandas das atividades sugeridas nesta proposta de alfabetização têm incidência direta, tanto no currículo escolar, como na relação da escola e de seus atores, com as demais instituições sociais, na medida em que algumas destas se constituem também em espaços educativos que precisam estar organicamente articulados ao funcionamento da escola. O planejamento escolar, portanto, deverá ser balizado de modo a incluir os parâmetros que operacionalizam as demandas para a implantação do processo proposto.

Por sua vez, a atuação docente precisa ocorrer com outras bases. É o papel de um agente transformador que está se exigindo do professor. Além das novas competências técnicas e instrumentais para desempenhar adequadamente a sua função educativa em sintonia com as demandas desta perspectiva alfabetizadora, o professor precisa tanto desenvolver o espírito crítico e a criatividade, como envolver-se ativamente com a sua comunidade, sendo um formador de opiniões.

Se este é um desafio ao professor, não cabe a ele a exclusividade para o seu enfrentamento. Fica clara a necessidade de um redirecionamento nos cursos de formação inicial de professores, bem como um processo de formação continuada em serviço que se articule organicamente ao trabalho docente, de modo a poder fornecer condições materiais, profissionais e intelectuais capazes de assegurar aos professores uma atuação educativa na perspectiva aqui proposta. 


\section{REFERÊNCIAS}

ANGOTTI, J. A.P. (1991). Fragmentos e totalidades no conhecimento científico e no ensino de ciências. São Paulo: Faculdade de Educação da USP. Tese de Doutorado.

ANGOTTI, J. A. P.; DELIZOICOV D. (1990). Metodologia do Ensino de Ciência. São Paulo: Cortez.

BINGLE, W. H.; GASKELL, P. J. (1994). Scientific literacy for decisionmaking and the social construction of scientific knowledge. In: Science \& Education, v. 78, n. 2, p. 185201, Australia.

BRASIL (1997a). Secretaria da Educação Fundamental. Parâmetros curriculares nacionais: Ciências Naturais. Brasília: MEC/SEF.

BRASIL (1997b). Secretaria da Educação Fundamental. Parâmetros curriculares nacionais: Arte. Brasília: MEC/SEF.

BYBEE, R. W. (1995). Achieving scientific literacy. In: The science teacher, v. 62, n. 7, p. 28-33, Arlington: United States, oct.

CAGLIARI, L. C. (1988). A leitura nas séries inicias. In: Leitura: teoria \& prática, Revista semestral da associação de Leitura do Brasil, n. 12, ano 7, Campinas-SP.

CAPES/UFRN (1984). Projeto Ensino de Ciências a partir de Problemas da Comunidade. Natal: Departamento de Educação, UFRN.

CAPES/UFRJ (1986). Física para a Escola Normal. Rio de Janeiro: Projeto Fundão, Equipe de Física. UFRJ.

CARVALHO, A.M.P. e LIMA,M.C.B. (2000). "Exercício de Raciocínio" em três linguagens: Ensino de Física nas Séries Iniciais. In: Programas e Resumos do VII EPEF. Florianópolis. SBF.

CAZELLI, S. (1992). Alfabetização científica e os museus interativos de ciência. Rio de Janeiro: Departamento de Educação PUC/RJ. Dissertação de Mestrado.

COBERN, W. W.; GIBSON, A T.; UNDERWOOD, S. A. (1995). Valuing Scientific Literacy. In: The science teacher, v. 62, n. 9, p. 28-31, Arlington: United States, dec.

DAL PIAN, M. C. et alii. (1985). Agricultura - Material de Apoio. Natal: Ed. Universitária UFRN.

n. 55 , p. 49-56.

DELIZOICOV, D. (1991). Conhecimento, tensões e transições. São Paulo: Faculdade de Educação da USP. Tese de Doutorado.

DELIZOICOV, D. (1993). Ensino de Física no Curso de Magistéiro do $2^{\circ}$ grau. In: Atas do X SNEF. Londrina, SBF.

FOUREZ, G. (1994). Alphabétisation scientifique et technique. Bruxelles, Belgium.

FRACALANZA, H. et alii. (1986). O ensino de ciências no primeiro grau. S. Paulo: Atual.

FRIZZO, M. N. e MARIN, E. B. (1989). O ensino de ciências nas Séries Iniciais. ljuí: UNIJUÍ.

GEPECISC (1996). Banco de dados de fontes bibliográficas para o ensino de ciências. Florianópolis: CED/UFSC. 
GIORDAN, M. (1997). Elaboração de projetos temáticos e telemáticos para o ensino de ciências: a química orgânica revista através da alimentação. In: Atlas do I Encontro Nacional de Pesquisa em Ensino de Ciências, Águas de Lindóia, SP, $27-29$ nov.

GRUPO DE ALFABETIZAÇÃO (1991). Alfabetização os pressupostos da prática. In: Espaços da escola. ljuí: UNIJUI , n. 2, p. 05-7.

HAZEN, R. M.; TREFIL J. (1995). Saber ciência. São Paulo: Cultura Editores Associados. HURD, P. D. (1998). Scientific literacy: new mind for a changing world. In: Science \& Education. Stanford, USA, n. 82, p. 407-416.

KRASILCHIK, M. (1992). Caminhos do ensino de ciências no Brasil. In: Em Aberto. Brasília, n. 55, p. 4-8.

LEAL, M. C.; SOUZA, G. G. (1997). Mito, ciência e tecnologia no ensino de ciências: o tempo da escola e do museu. In: Atlas do I Encontro Nacional de Pesquisa em Ensino de Ciências, Águas de Lindóia-SP, 27-29nov.

LEITE, Sérgio A S.; SOUZA, C. B. de (1995). A alfabetização nos cursos de habilitação para o magistério. In: Cadernos de Pesquisa, São Paulo, n. 94, p. 15-24, ago.

LIMA, M.C.B. (1992). Quente ou Frio. Rio de Janeiro: Ao Livro Técnico, (1992a). A Biruta e a Curiosa. Rio de Janeiro: Ao Livro Técnico. (1993). Não tem jeito, Cai. Rio de Janeiro: Ao Livro Técnico.

MEC (1994). Definição de Critérios para a avaliação dos livros didáticos de $1^{a}$ à $4^{a}$ séries. Brasília: FAE.

(1996). Guia de Livros didáticos de $1^{a}$ à $4^{a}$ séries. Brasília: FAE/CENPEC.

MOHR, A. (1994). A saúde na escola: análise de livros didáticos de $1^{a}$ à $4^{a}$ séries. Rio de Janeiro: Instituto de Estudos Avançados em Educação, FGV. Dissertação de Mestrado.

MORAIS, R. (1995). Ciências para Séries Iniciais e alfabetização. Porto Alegre: Sagra DC Luzzatto.

MORAIS, J. (1996). A arte de ler. UNESP.

MENDES SOBRINHO, J. A. C. (1998). Ensino de Ciências e Formação de Professores: Na escola Normal e no Curso de Magistério. Florianópolis: CED/UFSC. Tese de Doutorado.

MILLER, J. D. (1983). Scientific literacy: a conceptual and empirical review, In: Daedalus, n. 112 , p. 29-48.

MONTEIRO, M.T.F. (1993). Ciências na Alfabetização. In: Universidade e Aprendizado Escolar de Ciências. Projeto USP/BID. Formação de Professores de Ciências 1990-1993. S. Paulo: USP/CECAE.

ORÓ, I. (1999). Conhecimento do Meio Natural, In: ZABALA, Antoni (Org.). Como trabalhar os conteúdos procedimentais em aula, Porto Alegre: Artes Médicas Sul.

PERNAMBUCO, M.M. et alii. (1988). Projeto Ensino de Ciências a partir de Problemas da Comunidade. In: Ciência Integrada e/ou integração entre as Ciências: teoria e prática. Rio de Janeiro: Editora da UFRJ.

PERNAMBUCO, M. M. et alii. (1985). Saúde - Material de Apoio. Natal: Ed. Universitária UFRN.

PRETTO, N. D. L. (1983). Os livros de ciências de $1^{a}$ à $4^{a}$ séries do $1^{0}$ grau. Salvador: UFBA. Dissertação de Mestrado. 
RAMOS, E. M. F et alii. (2000). A física e a circunstância: elementos das crenças e idéias de professores e futuros professores do ensino fundamental. In: Programas e Resumos do VII EPEF. Florianópolis. SBF.

SÃO PAULO (1992). Ciências. Documento n. 5, São Paulo: Prefeitura Municipal.

SHEN, B. S. P. (1975). Science Literacy. In: American Scientist, v. 63, p. 265-268, may.-jun. SILVA FILHO, J. J. (1998). Computadores: super-heróis ou vilões? Um estudo das possibilidades do uso pedagógico da informática na Educação Infantil. Centro de Educação da Universidade Federal de Santa Catarina, Tese de Doutorado.

SOARES, M. B. (1985). As muitas facetas da alfabetização. In: Cadernos de Pesquisa, São Paulo, n. 52, p. 19 - 24.

(1998). Letramento: um tema em três gêneros, Belo Horizonte: Autêntica.

SOUZA, G. G. de et alii. (s/d). Revista científica e aprendizagem lúdica em sala de aula, s/l. VALLE, M. e MIRANDA, H. T. (1993). Ciências e Linguagem. In: Universidade e Aprendizado Escolar de Ciências. Projeto USP/BID. Formação de Professores de Ciências 1990-1993. S. Paulo: USP/CECAE.

VAZ, A. (1996). Saber Estratégico de Professores Primários: Pesquisa Crítica em Ensino de Ciências. In: Pró-Proposições. Vol 7, n 1[9], p.103-112.

\title{
SCIENTIFIC LITERACY IN THE EARLIER SERIES CONTEXT
}

\section{ABSTRACT}

The contribution of nature science teaching on earlier series of the fundamental education for the student's literacy process is analyzed. A bibliographical rescue of the works developed in Brazil, on the two last decades, about the subject, as well as, those produced in several countries talking about scientific literacy, propitiated the establishment of a comprehension for the scientific literacy process to be worked on earlier series. It's emphasized that the scientific literacy is a perpetual activity, being systematized at the scholastic space, but transcending its proportions to informal educational places, permeated for different media and speeches. It's presented a programming structure where some didactic-methodological initiatives take place, they can, allied with the appropriation of the student's written code, contribute on the scientific literacy process that needs to occur at the fundamental education circuit.

Key Words: Scientific Literacy; Teaching of Natural Sciences; Education in Sciences.

\author{
AUTORES/CORRESPONDÊNCIA \\ Leonir Lorenzetti \\ Universidade do Contestado - UnC-Caçador \\ Rua Marechal Deodoro, 50 apto 201 \\ 89.500-000 Caçador-SC \\ leo@conection.com.br
}




\section{Demétrio Delizoicov \\ Depto. Metodologia de Ensino \\ Universidade Federal de Santa Catarina \\ Florianópolis - SC \\ demetrio@ced.ufsc.br}

